\title{
Iron uptake and molecular recognition in Pseudomonas putida: receptor mapping with ferrioxamine B, coprogen B and their biomimetic analogues
}

\author{
Edouard Jurkevitch, ${ }^{1}$ Yitzhak Hadar, ${ }^{1}$ Yona Chen, ${ }^{2}$ Pnina Yakirevitch, ${ }^{3}$ \\ Jacqueline Libman ${ }^{3}$ and Abraham Shanzer ${ }^{3}$
}

\footnotetext{
1,2 Departments of 1Plant Pathology \&

Microbiology, and 2 Soil \& Water Sciences, Faculty of Agriculture, The Hebrew University of Jerusalem, Rehovot 76100, Israel

3 Department of Organic Chemistry, The Weizmann Institute of Science, Rehovot 76100, Israel
}

\author{
Author for correspondence: Y'itzhak Hadar. Tel: +9728481129 . Fax: +9728468785 \\ e-mail : CHET\%HUJIAGRI(a)VMS.HUJI.AC.IJ
}

This study shows that Pseudomonas putida possesses active uptake systems for $\mathrm{Fe}^{3+}$-ferrioxamine $\mathrm{B}$ (FOB) and $\mathrm{Fe}^{3+}$-coprogen B (Cop.B). These systems were characterized using natural and synthetic siderophores as structural probes. The synthetic analogues p178, p191, p239, p254 and p271 are a family of systematically modified linear retro-trishydroxamates that have shorter links between the ion binding groups relative to the natural compounds and possess chiral centres. They form a lower number of isomeric $\mathrm{Fe}^{3+}$ complexes relative to the natural compounds, and may be regarded as their specific conformers. Growth promotion and facilitated ${ }^{55} \mathrm{Fe}^{3+}$ uptake using both natural and synthetic siderophores were studied. The results obtained, along with those from competition experiments between the natural and the synthetic analogues demonstrate that: (i) the FOB and Cop.B uptake systems share common transport determinants; (ii) FOB and Cop. B make use of separate receptors; (iii) the Cop.B receptor is conformationally more demanding than the FOB receptor; and (iv) the FOB receptor has preference for the $\Lambda$-cis configuration although the natural siderophore is achiral. These results also demonstrate the usefulness of the synthetic analogues as structural probes. Some of these analogues simulate the natural counterparts as $\mathrm{Fe}^{3+}$ carriers, while others merely inhibit the action of the natural compounds by competing for the respective siderophore receptor.

\section{INTRODUCTION}

Fluorescent pseudomonads are widely found in the rhizosphere (Curl \& Truelove, 1986). They can promote plant growth and act as biocontrol agents (Bakker et al., 1990; Loper \& Buyer, 1991). Since Fe forms insoluble ferric hydroxides in solution, the amount of soluble $\mathrm{Fe}$ in the environment is minute (Lindsay, 1979). One of the mechanisms by which fluorescent pseudomonads exert their beneficial effects is by scavenging Fe via their own siderophore or via siderophores produced by other microorganisms (Bakker et al., 1990; Kloepper et al., 1980). Fluorescent pseudomonads are thus able to use various hydroxamate and catecholate siderophores produced by

Abbreviations: Cop., coprogen; Fc, ferrichrome; $F O B$, ferrioxamine B. other bacteria and fungi, such as those of the ferrichrome $(\mathrm{Fc})$ family (Jurkevitch et al., 1992a). The ability to utilize the siderophores of other micro-organisms probably confers an ecological advantage in the competition for $\mathrm{Fe}$ (Buyer \& Sikora, 1990; Crowley et al., 1991). A knowledge of the structural requirements for siderophore uptake in fluorescent pseudomonads thus provides a means to enhance or inhibit specific microbial populations.

Siderophore-mediated $\mathrm{Fe}$ uptake in bacteria involves several steps: First, the Fe complex is recognized by a receptor. It is then transported through one or two membranes, the $\mathrm{Fe}$ separated from the ligand, then the $\mathrm{Fe}^{3+}$ is metabolized or stored (Winkelmann, 1991). Recognition of the metal complex is usually receptor specific, a certain receptor being able to identify and 
transport one (or a few) siderophore(s) (having many structural features in common). In some cases, the domains that are important for recognition and transport have been determined. Relevant features involve the chirality of the coordination geometry around the metal centre (which can either be of a $\Delta$ or a $\Lambda$ configuration), the $\mathrm{Fe}$-surrounding residues, and the three-dimensional structure of the metal complex (Bergeron \& Weimar, 1990; Jurkevitch et al., 1992b, Winkelmann \& Braun, 1981). Some hydroxamate siderophores, which are produced by a wide range of fungi, actinomycetes and bacteria, adopt a $\Delta$ configuration around the Fe centre (coprogen); others are left-handed $(\mathrm{Fc})$, while still others form racemic mixtures (ferrioxamine).

Coprogen (Cop.) is a modified trimer of $N^{5}$-hydroxy$N^{5}$ (5-hydroxy-3-methyl-1-oxo-2-pentyl)-L-ornithine which adopts a $\Delta$-trans configuration around the metal centre (Wong et al., 1983). Coprogen B (Cop. B) is a closely related compound that differs from Cop. by substitution of the 3-acetyl residue with a hydrogen atom (Ernst \& Winkelmann, 1974). Both compounds have been shown to be actively taken up by fungi (Ernst \& Winkelmann, 1974) and bacteria (Braun \& Hantke, 1991).

Ferrioxamine B (FOB), produced by Streptomyces pilosus, is a linear trishydroxamic acid composed of alternating units of 1-amino-5-(hydroxyamino)pentane and succinic acid (Tufano \& Raymond, 1981). FOB represents an extreme case of configurational variability, in that it can form a total of five isomers when binding trivalent metal ions, each as racemic mixture (Leong \& Raymond, 1975). FOB mediates $\mathrm{Fe}$ uptake in fungi, actinomycetes and bacteria (Mor \& Barash, 1990; Muller \& Raymond, 1984; Rabsch \& Winkelmann, 1991).

Uptake of FOB and Cop. proceeds through two different receptors in Pantoea agglomerans, but it is unclear whether Escherichia coli possesses one receptor with dual function (Braun \& Hantke, 1991), or two distinct receptors, one for each compound (Berner et al., 1991; Nelson et al., 1992).

In a previous study, we showed that $\mathrm{Fc}$ promotes the growth of $P$. putida and mediates ${ }^{55} \mathrm{Fe}$ incorporation (Jurkevitch et al., 1992b). Using an original series of biomimetic analogues, we demonstrated that the $\Lambda$ configuration is an essential, but not sufficient feature for receptor recognition and further transport; the threedimensional shape and the bulkiness of the projecting side chains are also of importance. In this study, we show that Cop. B and FOB act as siderophores for P. putida. In order to probe for the structural requirements of the $\mathrm{FOB}$ receptor and their relation to Cop. recognition, we designed and synthesized synthetic FOB analogues that would preferentially (if not exclusively) adopt the $c$ is configuration, exhibit significant chiral preference for either the right- or the left-handed configurations, possess minimal conformational freedom, and thereby "freeze out' specific conformations of the natural $\mathrm{Fe}^{3+}-\mathrm{FOB}$ complexes.

\section{METHODS}

Bacterial strains. P. putida WCS358 and its siderophore minus $\left(\mathrm{Sid}^{-}\right)$Tn5-induced mutant JM218 were obtained from P. Weisbeek in Utrecht, The Netherlands. P. putida B10 was a kind gift from J. Buyer, Beltsville, MD, USA. P. putida St 3 was isolated in our laboratory.

Siderophores. Fc and Cop. B were from laboratory stock. FOB was purchased in the methylsulfonate form (Desferal) from Ciba-Geigy. Synthesis of the Fc analogues B5 and B9 has been described previously (Jurkevitch et al., 1992b).

Synthesis. The ferrioxamine analogues were prepared in essentially four steps as described by Yakirevitch et al. (1993).

Plate tests. The antibiosis plate test was carried out as described by Buyer \& Leong (1990). Soft agar $(0.6 \mathrm{ml})$ inoculated with approximately $10^{3}$ c.f.u. $\mathrm{ml}^{-1}$ of the test bacterium was poured over modified King's B (MKB) medium in $5 \mathrm{~cm}$ diameter Petri dishes. Twenty $\mu$ of a $10^{-3} \mathrm{M}$ solution of the test desferri compound was dropped onto a $6 \mathrm{~mm}$ diameter Whatman paper disk. The plates were incubated at $30^{\circ} \mathrm{C}$ and examined after 24 h.

For the Fe-siderophore complex utilization test, the bacteria were grown in liquid $\mathrm{MKB}$ medium and about $10^{3}$ c.f.u. were plated on $\mathrm{MKB}$ plates containing $400 \mu \mathrm{M} \alpha, \alpha^{\prime}$-dipyridyl. The bacteria were also grown in a liquid rhizosphere simulating medium (RSM) and plated on RSM containing $201 \mu \mathrm{M}$ ethylenediamine di-o-hydroxyphenylacetic acid (EDDHA) (Buyer $t$ al., 1989). Ten $\mu \mathrm{l}$ of a $10^{-4} \mathrm{M}$ solution of the Fe-siderophore complex was dropped on a Whatman paper disk. The plates were incubated as above.

Growth curves. The $\mathrm{Sid}^{-}$strain JM218 was used to test the efficiency of bacterial growth promotion in an Fe-free liquid medium. HEPES-succinate medium [HSM, containing $\left(\mathrm{g} \mathrm{l}^{-1}\right)$ : succinate, $4 ; \mathrm{K}_{2} \mathrm{HPO}_{4}, 0 \cdot 2 ;\left(\mathrm{NH}_{4}\right)_{2} \mathrm{SO}_{4}, 1 ; \mathrm{MgSO}_{4} .7 \mathrm{H}_{2} \mathrm{O}, 0 \cdot 2$; and HEPES, 11.91) was batch-treated for $4 \mathrm{~h}$ with Chelite $\mathrm{N}$ resin Serva, $10 \mathrm{~g} \mathrm{l}^{-1}$, decanted and filtered through a $0.45 \mu \mathrm{m}$ filter. The $\mathrm{pH}$ was then raised to $7 \cdot 2$ by addition of $10 \mathrm{M} \mathrm{NaOH}$ and the medium was autoclaved. Double-distilled water was used, and the glassware was washed with $6 \mathrm{M} \mathrm{HCl}$ followed by thorough rinsing with double-distilled water.

Polypropylene test-tubes $(50 \mathrm{ml})$ were filled with $10 \mathrm{ml}$ of the Chelite-treated HSM. The $\mathrm{Fe}^{3+}$-siderophores were added to a final concentration of $10^{-6} \mathrm{M}$, the tubes were inoculated with about $4 \times 10^{7}$ c.f.u. $\mathrm{ml}^{-1}$ and shaken at $28^{\circ} \mathrm{C}$. Samples were taken at appropriate intervals and optical density at $620 \mathrm{~nm}$ was recorded. Each treatment was performed in triplicate.

${ }^{55} \mathrm{Fe}$ uptake. The procedure for determining ${ }^{55} \mathrm{Fe}$ uptake described by de Weger et al. (1988) was used, with minor modifications. The mutant JM218 was used in all experiments. The bacterium was grown in a half-strength standard succinate medium (SSM) to an $\mathrm{OD}_{620}$ of $0 \cdot 4$, centrifuged for $15 \mathrm{~min}$ at 2500 r.p.m. then resuspended in fresh half-strength SSM to a final $\mathrm{OD}_{620}$ of 0.3 and incubated for $1 \mathrm{~h}$ in a water bath at $28{ }^{\circ} \mathrm{C}$. The labelled ${ }^{55} \mathrm{Fe}^{3+}$ complex was added to a final concentration of $1 \mu \mathrm{M}$. When appropriate, dinitrophenol (DNP) and potassium cyanide $\left(\mathrm{CN}^{-}\right)$were added $20 \mathrm{~min}$ before the labelled compound to a final concentration of 2 and $5 \mathrm{mM}$, respectively. Aliquots $(0.5 \mathrm{ml})$ were taken in duplicate, layered onto a mixture of octyl/dibutyl phthalate $(1: 2, \mathrm{v} / \mathrm{v}$ Sigma) and centrifuged. Counting was performed on a Beckman LS1801 counter. 

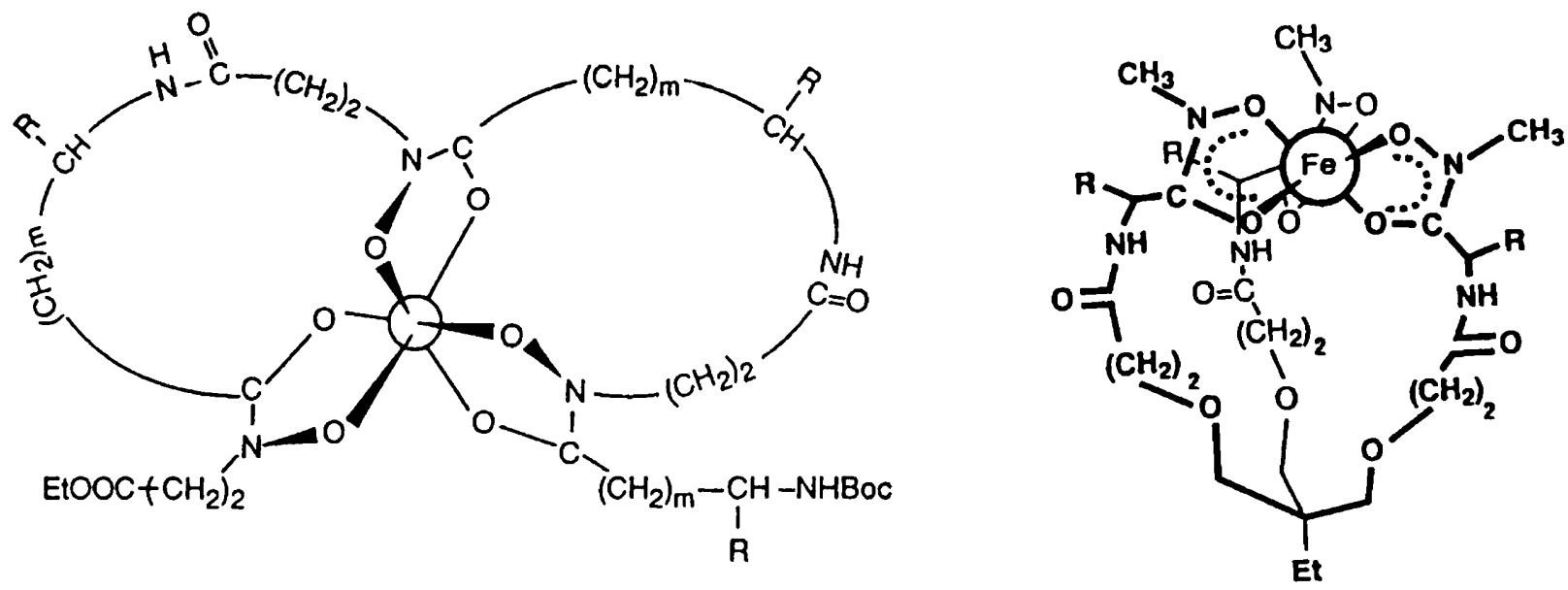

Fig. 1. Ferrioxamine analogues [left $P 178, m=0, R=i B u$ (L-Leu); $P 239, m=0, R=i B u$ ( $D-L e u) ; P 191, m=0, R=M e$ (LAla); P254, $m=2, R=$ CONEt $_{2}$ (L-Glu); P271, $m=2, R=$ CONEt $_{2}$ (D-Glu)] and ferrichrome analogues [right: B9, $R=H ; B 5$, $R=M e(L-A l a)]$.

\section{RESULTS}

\section{Design}

The synthesized ferrioxamine analogues are trimers of three monomers, each composed of a natural amino acid linked via hydroxamate bonds to $N$-hydroxyaminopropionic acid (Fig. 1). This design allows for a large variability by relying on natural amino acids as building blocks. Shortening the spacers between the binding sites relative to those of FOB ( $m=0$ and $m=2$, respectively; Fig. 1) restricts the number of possible coordination isomers to those possessing cis geometry. Incorporation of asymmetric centres induces chiral preference for either the right-or left-handed cis configuration.

Circular dichroism spectroscopy of the $\mathrm{Fe}^{3+}$ complexes demonstrated preferred right-handedness when L-amino acid components were used. Quite remarkably, the extent of chiral preference for the $\Delta$-cis configuration (when Lamino acids were used) varied substantially with the nature of the amino acid. While the chiral preference was small for the Ala and Leu derivatives, it was larger for the Asp derivative, and particularly large for the Glu derivatives. The enhanced chiral preference of the Asp derivative suggests the presence of specific non-covalent interactions between the projecting amide groups $\mathrm{CH}_{2} \mathrm{CONLt}_{2}$ and the backbone and/or $\mathrm{Fe}^{3+}$ centre of the molecule. The greater optical purity of the Glu derivatives is attributed to the extended amino acid bridges, which tend to lower the strain in the complex. A more detailed description of the compounds, their synthesis and coordination chemistry is given in Yakirevitch et al. (1993).

\section{Growth promotion and antibiosis plate tests}

Plate tests showed that $P$. putida St3, WCS358, B10 and JM218 (the Sid ${ }^{-}$derivative of WCS358) are able to grow in the presence of the siderophores Cop. B and FOB.
When Cop. B or FOB were used as sole Fe source in plates containing EDDHA or $\alpha, \alpha^{\prime}$-dipyridyl, growth halos of bacteria 25 to $45 \mathrm{~mm}$ and 35 to $50 \mathrm{~mm}$ in diameter, respectively, were measured after 18 to $24 \mathrm{~h}$ incubation at $30{ }^{\circ} \mathrm{C}$. None of the $\mathrm{Fe}$ complexes of the synthetic siderophores p178, p191, p239, p254 and p271 could sustain bacterial growth.

Inhibitory activity of the desferri-compounds was also tested. Application of $20 \mu \mathrm{l}$ of a $10^{-3} \mathrm{M}$ solution of Cop. B or FOB as free ligands resulted in normal growth of the colonies around the paper disks, again indicating that the bacteria were able to use the $\mathrm{Fe}$-siderophore complex formed with residual Fe from the growth medium. The synthetic siderophore analogues p178, p191 and p239 did not exhibit antibiotic activity towards strain JM218. However, application of the desferri compounds p254 and p271 resulted in a clear zone of inhibition around the paper disks. This indicates that these latter compounds are totally unavailable as Fe sources for strain JM218. Since the control treatments, including the Fe complexes of the compounds did not show any deleterious effects, it can be concluded that $\mathrm{Fe}$ immobilization was the cause of the inhibition.

\section{Growth in liquid medium}

The growth-promoting ability of Fe-FOB and its biomimetic analogues was studied in a liquid medium treated with Chelite $\mathrm{N}$ to remove residual Fe. As seen in Fig. 2, the cells grew very poorly in the control treatment, while $\mathrm{Fe}-\mathrm{FOB}$ promoted strong growth of the bacterium, with a doubling time of about $1.75 \mathrm{~h}$. The Fe complexes of the synthetic analogues p178, p191 and p239 promoted the growth of JM218, but not as efficiently as the natural siderophores. Although the lag period was longer the slope of the curves differed little and generation times of 1.8 to $2 \mathrm{~h}$ were recorded. In agreement with the plate 


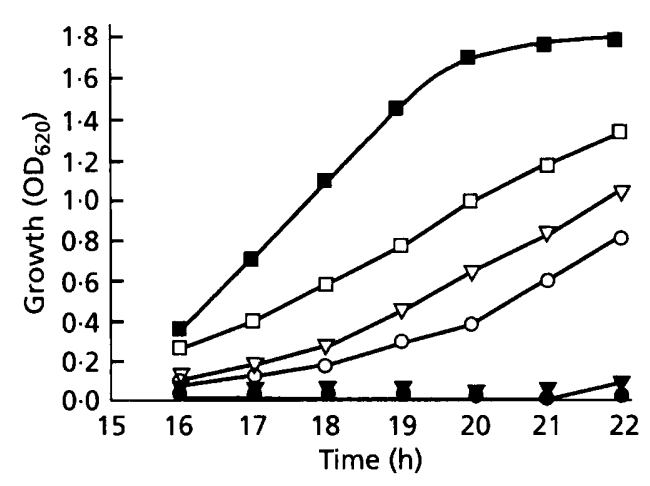

Fig. 2. Growth of mutant JM218 in Chelite-treated HSM with ferrioxamine $B(\square)$, and the ferrioxamine $B$ analogues p178 $(O)$, p191 ( $\square)$, p239 ( $\nabla)$, p254 ( $\nabla)$ and p271 (O) as iron sources. $\diamond$, Control (no added iron source).

experiments, the Fe complexes of p254 and its enantiomer p271 were totally ineffective in promoting bacterial growth. When Cop. B was tested in identical experiments, it behaved similarly to FOB.

\section{${ }^{55}$ Fe uptake}

${ }^{55} \mathrm{Fe}$ uptake mediated by Cop. B and FOB was demonstrated (Fig. 3). The two compounds mediated ${ }^{55} \mathrm{Fe}$ uptake similarly, showing a linear uptake response during the $20 \mathrm{~min}$ experiment. About 90 and $120 \mathrm{pmol} \mathrm{Fe}$ $(\mathrm{mg} \mathrm{dry} \mathrm{wt})^{-1}$ were incorporated after $20 \mathrm{~min}$ for Cop. B and FOB uptake, respectively. Uptake was strongly reduced by the inhibitory compounds potassium cyanide and dinitrophenol, as in Fc- and B9-mediated uptake (Table 1). The $K_{\mathrm{m}}$ values for ${ }^{55} \mathrm{Fe}$ uptake mediated by both FOB and Cop.B were calculated using data from concentration dependent experiments. The apparent $K_{\mathrm{m}}$ values were $0.09 \mu \mathrm{M}$ and $0.22 \mu \mathrm{M}$ for Cop. B- and FOB-
Table 1. Inhibition of ${ }^{55} \mathrm{Fe}$ uptake mediated by ferrichrome ( $\mathrm{FC}$ ), coprogen B (Cop.B), and ferrioxamine $B(F O B)$ and their biomimetic analogues by the respiratory inhibitors dinitrophenol (DNP) and potassium cyanide $\left(\mathrm{CN}^{-}\right)$

\begin{tabular}{|c|c|c|c|c|c|c|c|}
\hline \multirow[t]{3}{*}{ Inhibitor } & \multicolumn{7}{|c|}{ Percentage inhibition } \\
\hline & \multicolumn{7}{|c|}{${ }^{55} \mathrm{Fe}-$ siderophore: } \\
\hline & Fc & Cop. B & FOB & B9 & p178 & p191 & p239 \\
\hline $\mathrm{DNP}(2 \mathrm{mM})$ & 96 & 86 & 71 & 93 & - & & \\
\hline $\mathrm{CN}^{-}(5 \mathrm{mM})$ & 95 & 91 & 72 & 99 & 78 & 89 & 81 \\
\hline
\end{tabular}

mediated uptake, respectively. The synthetic analogues p178, p191 and p239 mediated ${ }^{55} \mathrm{Fe}$ uptake, but showed a different uptake pattern (Fig. 3). After $3 \mathrm{~min}$, the amount of ${ }^{55} \mathrm{Fe}$ associated with the cells was about three times higher than that for FOB- or Cop. B-mediated uptake (Fig. 3). The final concentration of Fe was about 110 pmol $(\mathrm{mg} \text { dry } w t)^{-1}$ resulting in a flatter uptake curve. Uptake of ${ }^{55} \mathrm{Fe}$ mediated by these three analogues was reduced by the addition of $\mathrm{CN}^{-}$to the incubation medium, demonstrating active uptake (Table 1). Compounds p254 and p271 did not promote appreciable ${ }^{55} \mathrm{Fe}$ uptake (Fig. 3).

\section{Competition experiments}

Competition experiments between the natural and the synthetic siderophores were performed to: (i) determine whether Fe uptake mediated by the siderophores Fc, FOB and Cop. B shares common components of the transport system; (ii) trace the structural requirements for recognition by these components. Uptake of ${ }^{55} \mathrm{Fe}-\mathrm{Cop} . \mathrm{B}$ was inhibited by increasing concentrations of cold $\mathrm{Fe}-\mathrm{Fc}$ and of the ferrichrome analogue $\mathrm{Fe}-\mathrm{B} 9$ derived from

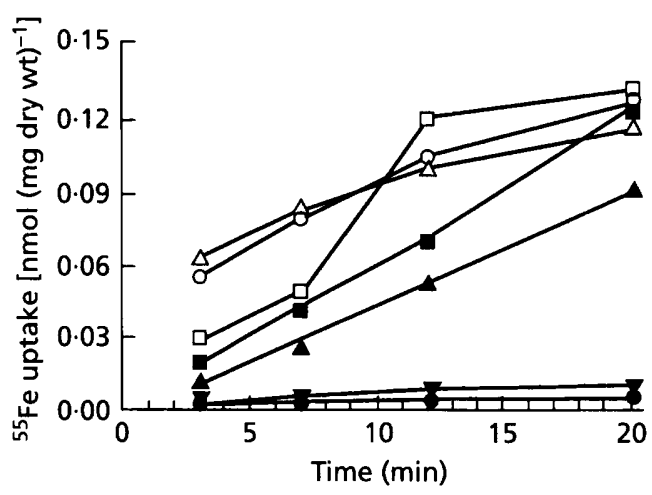

Fig. 3

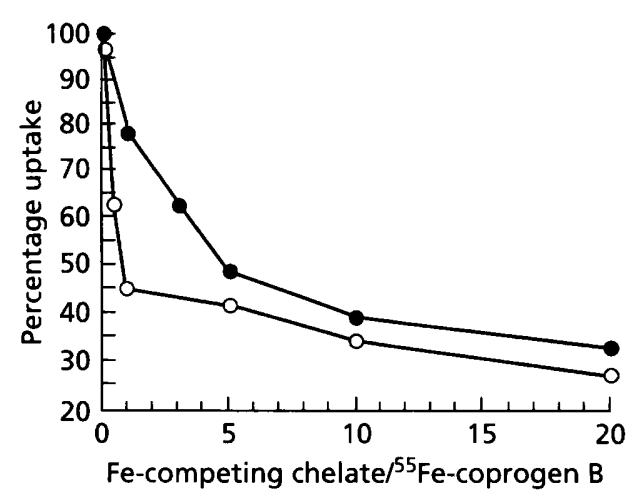

Fig. 4

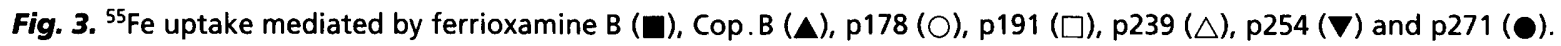

Fig. 4. Percentage of ${ }^{55} \mathrm{Fe}$ uptake mediated by Cop. $B$ in the presence of increasing concentrations of Fe-ferrichrome $(O)$ and Fe-B9 (O). 
Table 2. Inhibition of ferrioxamine $B(1 \mu M)$-mediated ${ }^{55} \mathrm{Fe}$ uptake by 'cold' Fe-coprogen B (Fe-Cop. B), Fe-ferrichrome ( $\mathrm{Fe}-\mathrm{FC})$ and the ferrichrome analogue Fe-B9

\begin{tabular}{|c|c|c|c|c|}
\hline \multirow{2}{*}{$\begin{array}{l}\text { Competing } \\
\text { siderophore }\end{array}$} & \multirow{2}{*}{ Concn $(\mu \mathrm{M}) \ldots$} & \multicolumn{3}{|c|}{ Percentage inhibition } \\
\hline & & 1 & 3 & 5 \\
\hline $\mathrm{Fe}-\mathrm{Cop} . \mathrm{B}$ & & 47 & 50 & 59 \\
\hline $\mathrm{Fe}-\mathrm{Fc}$ & & 49 & 58 & 71 \\
\hline $\mathrm{Fe}-\mathrm{B} 9$ & & 18 & 31 & 40 \\
\hline
\end{tabular}

Table 3. Inhibition of ferrioxamine $B$ (FOB)- and coprogen B (Cop. B)-mediated ${ }^{55} \mathrm{Fe}$ uptake $(1 \mu \mathrm{M})$ by 'cold' Fe-FOB analogues $(10 \mu \mathrm{M})$

\begin{tabular}{|lccccc|}
\hline & \multicolumn{5}{c|}{ Percentage inhibition } \\
\cline { 2 - 6 } & \multicolumn{5}{c}{ Biomimetic analogue: } \\
& p178 & p191 & p239 & p254 & p271 \\
\hline Fe-Cop.B & 46 & 53 & 42 & 0 & $2 \cdot 5$ \\
Fe-FOB & 51 & 46 & 65 & 22 & 52 \\
\hline
\end{tabular}

glycine (Jurkevitch et al., 1992b) (Fig. 4). Equimolar concentrations of $\mathrm{Fe}-\mathrm{Fc}$ and $\mathrm{Fe}-\mathrm{B} 9$ reduced ${ }^{55} \mathrm{Fe}$ uptake mediated by Cop. B by $55 \%$ and by $22 \%$, respectively. Similarly, FOB-mediated ${ }^{55} \mathrm{Fe}$ uptake was strongly affected by increased concentrations of the competing siderophores $\mathrm{Fe}-\mathrm{Fc}, \mathrm{Fe}-\mathrm{Cop} . \mathrm{B}$ and $\mathrm{Fe}-\mathrm{B} 9$ (Table 2). The data suggest that these siderophores use at least one common component in their uptake systems.

The Fe complex of the optically pure ferrichrome analogue $B 5(\Lambda)$ which blocks the Fc receptor (Jurkevitch et al., 1992b) was shown to have no effect on ${ }^{55} \mathrm{Fe}$ uptake mediated by either Cop. B or FOB. These siderophores must therefore mediate $\mathrm{Fe}$ uptake through one or two receptors that are different from that of Fc. Differential effects of the synthetic Fe-p254 $(\Delta)$ and Fe-p271 $(\Lambda)$ on the extent of Fe uptake mediated by Cop. B and FOB shows that these make use of different receptors: neither $\mathrm{Fe}-\mathrm{p} 254$ nor Fe-p271 inhibited ${ }^{55} \mathrm{Fe}$ uptake mediated by Cop. B (Table 3). However, both Fe-p254 and Fe-p271 affected FOB-mediated ${ }^{55} \mathrm{Fe}$ uptake with greatly different efficiencies. The former reduced $\mathrm{FOB}$-mediated ${ }^{55} \mathrm{Fe}$ incorporation by $22 \%$ and the latter by $52 \%$ (Table 3). The Fe complexes of compounds p178, p191 and p239, which are linear Cop. and ferrioxamine analogues of mixed chirality, inhibited both FOB- and Cop. B-mediated ${ }^{55} \mathrm{Fe}$ uptake, although at various levels (Table 3).

\section{DISCUSSION}

This study focused on the uptake of Fe via the linear siderophores Cop. B and FOB. We showed that these siderophores are active in fluorescent pseudomonads, being able to promote the growth of cells when supplied as the sole Fe source. U'sing natural siderophores and synthetic analogues as probes, and examining both their action as $\mathrm{Fe}$ carriers and their mutual inhibitory properties, we obtained qualitative information on the structural requirements of several hydroxamate siderophore Fe transport systems.

Uptake of ${ }^{55} \mathrm{Fe}$ mediated by FOB and Cop. B, as well as by $\mathrm{Fc}$, was shown to be an active process, probably involving the protonmotive force since it is inhibited by DNP as shown earlier for pseudobactin-mediated Fe uptake (de Weger $e$ t al., 1991). FOB- and Cop. B-mediated uptake of Ge showed high $K_{\mathrm{m}}$ values $(0.22$ and $0.09 \mu \mathrm{M}$, respectively). The uptake systems of these natural siderophores (Fc, Cop. B and FOB) must share a common component since ${ }^{55} \mathrm{Fe}$ uptake mediated by any of these compounds was decreased in the presence of 'cold' complexes of each of the other siderophores. This observation is reminiscent of the Fe uptake system of Escherichia coli where the periplasmic FhuD protein is able to bind siderophores with widely differing chemical structures such as Fc, Cop. and aerobactin (Koster \& Braun, 1990). The siderophores are then presumably passed to the cytoplasmic membranebound FhuB protein (Koster, 1991). Whether FhuD is free in the periplasmic space is unknown (Koster \& Braun, 1990). Huschka et al. (1985) have demonstrated that although the transport system for Fc and Cop. is shared in Neurospora crassa each compound has a specific receptor. More recently, Dori et al. (1990) have shown that in Gaeumannomyces graminis var. tritici, the siderophores dimerium acid, Cop. B, rhotorulic acid and Fc share a common transport system.

Competition experiments between FOB and Cop. B and synthetic analogues have enabled us to distinguish between different components of the siderophores' transport systems as well as to trace structural requirements for recognition by these components.

Compounds $\mathrm{B} 5$ and $\mathrm{B} 9$ are $\mathrm{C}_{3}$-symmetric $\mathrm{Fc}$ analogues (Fig. 1). B5 is chiral, adopts preferentially the $\Lambda$-cis configuration and has been shown to block the Fc receptor of $P$. putida. B9 is achiral and acts as an Fc substitute by promoting bacterial growth and ${ }^{55} \mathrm{Fe}$ uptake (Jurkevitch et al., 1992b). Inhibition of FOB- and Cop. B-mediated ${ }^{55} \mathrm{Fe}$ uptake by natural $\mathrm{Fc}$ and analogue $\mathrm{B} 9$ (Table 2) but not by analogue $\mathrm{B} 5$ - which merely blocks the Fc receptor - demonstrates the involvement of common components, but separate receptors for $\mathrm{Fc}$ and $\mathrm{FOB} / \mathrm{Cop}$. B transport systems.

Compounds p178, p191 and p254 are linear trishydroxamates possessing L-Leu, L-Ala and L-Glu amino acid residues respectively. p239 (D-Leu) is enantiomeric to $\mathrm{p} 178$, and $\mathrm{p} 271$ (D-Glu), is enantiomeric to p254. Although the Fe complexes of the shorter homologues p178, p191 and p239 were unable to promote growth in plate experiments, they supported growth enhancement in liquid medium. Furthermore, they effectively facilitated ${ }^{55} \mathrm{Fe}$ uptake which could be inhibited by the presence of cyanide. This demonstrates their availability as Fe carriers and their action to be dependent upon an energy-driven 
process. The $\mathrm{Fe}$ chelators used in the plates might therefore have interfered with the synthetic analogues (Berner et al., 1991). The fact that ${ }^{55} \mathrm{Fe}$ uptake did not follow first-order kinetics suggests some non-specific absorption of the complexes at the initial stages. This does not however, change the overall conclusions.

Both transport systems, that of FOB and that of Cop. B may be used by the shorter analogues (p178, p191 and p239), as shown by the inhibitory effects of these on FOBand Cop. B-mediated ${ }^{55} \mathrm{Fe}$ uptake (Tables 2 and 3). This may be attributed to their small diameter which facilitates adaptation to their respective recognition sites. The longer homologues (p254 and p271) fit to the FOB receptor, but not to the Cop. B receptor. They inhibited FOB-mediated ${ }^{55} \mathrm{Fe}$ uptake without acting as Fe carriers, but had no effect on Cop. B-mediated ${ }^{55} \mathrm{Fe}$ uptake. Moreover, the complex adopting a preferential $\Lambda$ configuration (derived from $\mathrm{p} 271$ ) was found to be a two- to threefold better inhibitor than its enantiomer derived from $\mathrm{p} 254$. The latter observations indicate: (i) the presence of different receptors for the FOB and Cop. B transport systems, and (ii) higher structural discrimination by the Cop. B receptor. Most remarkable is the chiral preference for the $\Lambda$ configuration ( $\mathrm{p} 271$ ) exhibited by the FOB receptor, which might imply that an 'archaic' FOB possessed chiral centres.

In conclusion, we have shown that the Fc, FOB and Cop.B transport systems of $P$. putida contain distinct receptors, but common transport proteins. Furthermore the Fc and FOB receptors may specifically be blocked with selected synthetic analogues (B9 and p271). In this respect, synthetic analogues may exceed the specificity of the natural siderophores, opening the possibility of selective growth inhibition. On the other hand, some synthetic compounds - like p178, p191 and p239-may exhibit dual activity, substituting both FOB and Cop. B as carriers and introducing 'broad spectrum' growth promoters. The effect of the synthetic compounds may, however, differ between micro-organisms. Thus, the shorter analogues p178, p191 and p239 exerted FOB-like activity towards Hafnei alvei, Coprogen-like activity towards E. coli and both activities towards Pantoea agglomerans (Berner et al., 1991) as towards P. putida. However, the longer homologues p254 and p271 also show dual FOB and Cop. activities independently of their chirality in $P$. agglomerans (G. Winkelmann, personal communication) in contrast to $P$. putida. These findings demonstrate that species-dependent differences in the structural characteristics of related siderophore uptake systems may prevail. Whether these differences can be employed for the synthesis of species-specific growth promoting or growth inhibiting agents remains to be established.

\section{ACKNOWLEDGEMENTS}

We thank the binational Israel-USA Bard fund for supporting this research. We are grateful to P. Weisbeeck (Utrecht, Holland) and to J. Buyer (Beltsville, MD, USA) for providing us with the bacterial strains and to Mrs R. Lazar for technical assistance in the preparation of the synthetic analogues.

\section{REFERENCES}

Bakker, P. A. H. M., van Peer, R. \& Schippers, B. (1990). Specificity of siderophore receptors and biocontrol by Pseudomonas spp. In Biological Control of Soil-Borne Plant Pathogens, pp. 143-164. Edited by D. Hornby. Wallington: CAB International.

Barany, G. \& Merrifield, R. B. (1980). The Peptides: Analysis, Synthesis, Biology. Edited by E. Gross \& E. Meinhofter. New York: Academic Press.

Bergeron, R. J. \& Weimar, W. R. (1990). Kinetics of iron acquisition from ferric siderophores by Paracoccus denitrificans. J Bacteriol 172, 2650-2657.

Berner, I., Yakirevitch, P., Libman, J., Shanzer, A. \& Winkelmann, G. (1991). Chiral linear hydroxamates as biomimetic analogues of ferrioxamine and coprogen and their use in probing siderophorereceptor specificity in bacteria and fungi. Biol Metals 4, $186-191$.

Braun, V. \& Hantke, G. (1991). Genetics of bacterial iron transport. In Handbook of Microbial Iron Cbelates, pp. 107-138. Edited by G. Winkelmann. Boca Raton, FL: CRC Press.

Buyer, J. S. \& Leong, J. (1986). Iron transport-mediated antagonism between plant growth-promoting and plant deleterious Pseudomonas strains. J Biol Chem 261, 791-794.

Buyer, J. S. \& Sikora, L. J. (1990). Rhizosphere interactions and siderophores. Plant Soil 129, 101-107.

Buyer, J. S., Sikora, L. J. \& Chaney, R. L. (1989). A new growth medium for the study of siderophore-mediated interactions. Biol Fertil Soils 8, 97-101.

Crowley, D. E., Wang, Y. C., Reid, C. P. P. \& Szaniszlo, P. J. (1991). Mechanisms of iron acquisition from siderophores by microorganisms and plants. Plant Soil 130, 179--198.

Curl, E. A. \& Truelove, B. (1986). The Rhizosphere. Advanced Series in Agricultural Sciences. Berlin: Springer-Verlag.

de Weger, L. A., van Arendonk, J. J. C. M., Recourt, K., van der Hofstad, G. A. J. M., Weisbeek, P. J. \& Lugtenberg, B. (1988). Siderophore-mediated uptake of $\mathrm{Fe}^{3+}$ by the plant growthstimulating Pseudomonas putida strain WCS358 and by other rhizosphere microorganisms. J Bacteriol 170, 4693-4698.

Dori, S., Solel, Z., Kashman, Z. \& Barash, I. (1990). Characterization of hydroxamate siderophores and siderophore mediated iron uptake in Gaeumannomyces graminis var. tritici. Physiol Mol Plant Pathol 37, 95-106.

Ernst, J. \& Winkelmann, G. (1974). Metabolic products of microorganisms. 135. Uptake of iron by Neurospora crassa. IV. Iron transport properties of semisynthetic coprogen derivatives. Arch Microbiol 100, 271-282.

Huschka, H., Naegeli, H. U., Leuenberger-Ryf, H., Keller-Schierlein, W. \& Winkelmann, G. (1985). Evidence for a common siderophore transport system but different receptors in Neurospora crassa. J Bacteriol 162, 715-721.

Jurkevitch, E., Hadar, Y. \& Chen, Y. (1992a). Differential siderophore utilization by soil and rhizosphere bacteria. Appl Environ Microbiol 58, 119-124.

Jurkevitch, E., Hadar, Y., Chen, Y., Libman, J. \& Shanzer, A. (1992b). Iron uptake and molecular recognition in Pseudomonas putida: receptor mapping with ferrichrome and its biomimetic analogs. J Bacteriol 174, 78-83.

Kloepper, J. W., Leong, J., Teintze, M. \& Schroth, M. N. (1980). Enhanced plant growth by siderophores produced by plant growthpromoting rhizobacteria. Nature 286, 885-886.

Koster, W. (1991). Iron(III) hydroxamate transport across the cytoplasmic membrane of E. coli. Biol Metals 4, 2332.

Koster, W. \& Braun, V. (1990). Iron(III) hydroxamate transport in 
Eschericliac coli: substrate binding to the periplasmic FhuD protein. J Biol Cluem 265, 21407-21410.

Leong, J. \& Raymond, K. N. (1975). Coordination isomers of biological iron transport compounds. IV. Geometrical isomers of chromic desferrioxamine B. J Am Chem Soc 97, 293-296.

Lindsay, W. L. (1979). Chemical Equilibrium in Soils. New York: John W'iles \& Sons.

Loper, J. E. \& Buyer, J. S. (1991). Siderophores in microbial interactions on plant surfaces. Mol Plant-Microbe Interact 4, 5-13.

Mor, H. \& Barash, I. (1990). Characterization of siderophoremediated iron transport in Geotrichum candidum, a non-siderophore producer. Biol Metals 2, 209-213.

Muller, G. \& Raymond, K. N. (1984). Specificity and mechanism of ferrioxamine-mediated iron transport in Streptomyces pilosus. $J$ Bacteriol 160, 304-312.

Nelson, M., Carrano, C. J. \& Szaniszlo, P. J. (1992). Identification of the ferrioxamine B receptor, FoxB, in Escherichia coli $\mathrm{K} 12$. Bio.Metals 5, 37-46.

Rabsch, W. \& Winkelmann, G. (1991). The specificity of bacterial siderophore receptors probed by bioassays. Biol Metals 4, 244-250.
Tufano, T. P. \& Raymond, K. N. (1981). Coordination chemistry of microbial iron transport compounds. 21. Kinetics and mechanisms of iron exchange in hydroxamate siderophore complexes. $J \mathrm{Am}$ Chem Soc 103, 6617-6624.

Winkelmann, G. (1991). Specificity of iron transport in bacteria and fungi. In Handbook of Microbial Iron Chelates, pp. 65-106. Edited by G. Winkelmann. Boca Raton, FL: CRC Press.

Winkelmann, G. \& Braun, V. (1981). Stereoselective recognition of ferrichrome by fungi and bacteria. FEMS Microbiol Lett 11, $237-241$.

Wong, G. B., Kappel, M. J., Raymond, K. N., Matzanke, B. \& Winkelmann, G. (1983). Coordination chemistry of microbial iron transport compounds. 24. Characterization of coprogen and ferricrocin, two ferric hydroxamate siderophores. J.Am Chem Soc 105, 810-815.

Yakirevitch, P., Rochel, N., Albrecht-Gary, A. M., Libman, J. \& Shanzer, A. (1993). Ferrioxamines and their iron(III) coordination properties. Inorgan Chem 32, 1779-1787.

Received 26 August 1993; revised 21 January 1994; accepted 25 January 1994. 